\title{
Large-scale application of the flood damage model RAilway Infrastructure Loss (RAIL)
}

\author{
Patric Kellermann $^{1}$, Christine Schönberger ${ }^{2}$, and Annegret H. Thieken ${ }^{1}$ \\ ${ }^{1}$ Institute of Earth and Environmental Science, University of Potsdam, Karl-Liebknecht-Straße 24-25, \\ 14476 Potsdam, Germany \\ ${ }^{2}$ ÖBB-Infrastruktur AG, Nordbahnstrasse 50, 1020 Vienna, Austria \\ Correspondence to: Patric Kellermann (patkell@uni-potsdam.de)
}

Received: 3 August 2016 - Published in Nat. Hazards Earth Syst. Sci. Discuss.: 10 August 2016

Revised: 19 October 2016 - Accepted: 20 October 2016 - Published: 10 November 2016

\begin{abstract}
Experience has shown that river floods can significantly hamper the reliability of railway networks and cause extensive structural damage and disruption. As a result, the national railway operator in Austria had to cope with financial losses of more than EUR 100 million due to flooding in recent years. Comprehensive information on potential flood risk hot spots as well as on expected flood damage in Austria is therefore needed for strategic flood risk management. In view of this, the flood damage model RAIL (RAilway Infrastructure Loss) was applied to estimate (1) the expected structural flood damage and (2) the resulting repair costs of railway infrastructure due to a 30-, 100- and 300-year flood in the Austrian Mur River catchment. The results were then used to calculate the expected annual damage of the railway subnetwork and subsequently analysed in terms of their sensitivity to key model assumptions. Additionally, the impact of risk aversion on the estimates was investigated, and the overall results were briefly discussed against the background of climate change and possibly resulting changes in flood risk. The findings indicate that the RAIL model is capable of supporting decision-making in risk management by providing comprehensive risk information on the catchment level. It is furthermore demonstrated that an increased risk aversion of the railway operator has a marked influence on flood damage estimates for the study area and, hence, should be considered with regard to the development of risk management strategies.
\end{abstract}

\section{Introduction}

The railway transportation system in Austria is of major importance for the European transit of passengers and goods from north to south and east to west. In addition, the railway lines are essential for the accessibility of lateral alpine valleys and, thus, contribute to economic and societal welfare. However, experience has shown that river floods can significantly hamper the reliability of railway networks and cause extensive structural damage to parts of the infrastructure and disruption in the network (Nester et al., 2008; Moran et al., 2010a, b; Kellermann et al., 2015). Particularly in recent years, the national railway operator in Austria, the Austrian Federal Railways (ÖBB), had to cope with financial losses of more than EUR 100 million due to flooding. For example, the 100-year Morava River flood in Lower Austria in 2006 washed parts of the Northern Railway (Nordbahn) away and caused repair costs of more than EUR 41.4 million (Moran et al., 2010a; ÖBB-Infrastruktur AG, personal communication, 2014) and a complete shutdown of passenger and freight operations for several months along the Austrian Northern Railway (Moran et al., 2010b; Kellermann et al., 2015). The severe flooding in central Europe in May and June 2013 had even more serious consequences for the ÖBB, costing a total of more than EUR 75 million (ÖBB Infrastruktur AG, 2014), caused by heavy direct damage at multiple track sections as well as extensive service disruptions, including loss due to further rainfall-triggered events (e.g. debris flows, torrential processes). Such events clearly show that railway infrastructure and service are highly vulnerable to floods and furthermore point out the importance of a comprehensive flood risk management. 
Given the significance of flood hazards as well as other natural hazards, e.g. debris flows and extreme weather events (e.g. Fuchs et al., 2015; see Fig. 1), the ÖBB maintains its own department for natural hazard management and additionally cultivates partnerships with various stakeholders at different administrative levels. Figure 1 provides a schematic overview of the ÖBB risk management cycle and the most important partners involved. In the context of risk reduction, the ÖBB follows two main strategies (Otto et al., 2014; see Fig. 1). One strategy focusses on structural risk reduction measures, i.e. planning, design, implementation and maintenance of technical protection measures such as embankments and torrent control structures. This strategy is mainly applied to reduce risks from avalanches, rock falls and torrents, particularly in alpine areas, but also in lowland river catchments, where appropriate. However, the implementation of technical protection measures is often not feasible either for economic reasons or due to aspects of nature and landscape conservation (Brauner, 2011). Moreover, technical measures are limited in ensuring a commensurate level of safety for railway operations in Alpine topography (Kellermann et al., 2016a). Hence, in recent years, natural hazard and risk management has shifted from pure technological and protective approaches towards a more integrated risk management strategy including a variety of non-structural measures in order to mitigate (residual) risks from natural hazards. Accordingly, the second main risk management strategy of the ÖBB also puts strong emphasis on non-structural, precautionary and preparatory risk mitigation measures, i.e. monitoring and early warning systems with organizational measures such as speed limits and track closures in dangerous situations (Kellermann et al., 2016a).

To support strategic flood risk management and decisionmaking with a focus on structural measures, reliable information on potential flood risk hot spots as well as on expected flood damage is needed. However, modelling flood damage to transportation infrastructure is either neglected in natural hazards and risks research or only roughly estimated by a fixed percentage share of property losses - as practised, for example, in the Multi-Coloured Manual (MCM) (e.g. Penning-Rowsell and Chatterton, 1977; Penning-Rowsell et al., 1992, 2005, 2010, 2013). Although a few established flood damage models such as the Rhine Atlas damage model (RAM) (ICPR, 2001) and the Damage Scanner model (DSM) (Klijn et al., 2007) consider direct flood damage to infrastructure by dedicated depth-damage curves, their estimations are based only on aggregated, low-resolution CORINE land cover data containing a large variety of urban infrastructure and lifeline elements (Bubeck et al., 2011; Jongman et al., 2012). As a consequence, the model outputs of RAM and DSM only insufficiently reflect damage to linear structures and furthermore provide no detailed information on the individual shares of damage to transport infrastructure (Bubeck et al., 2011).

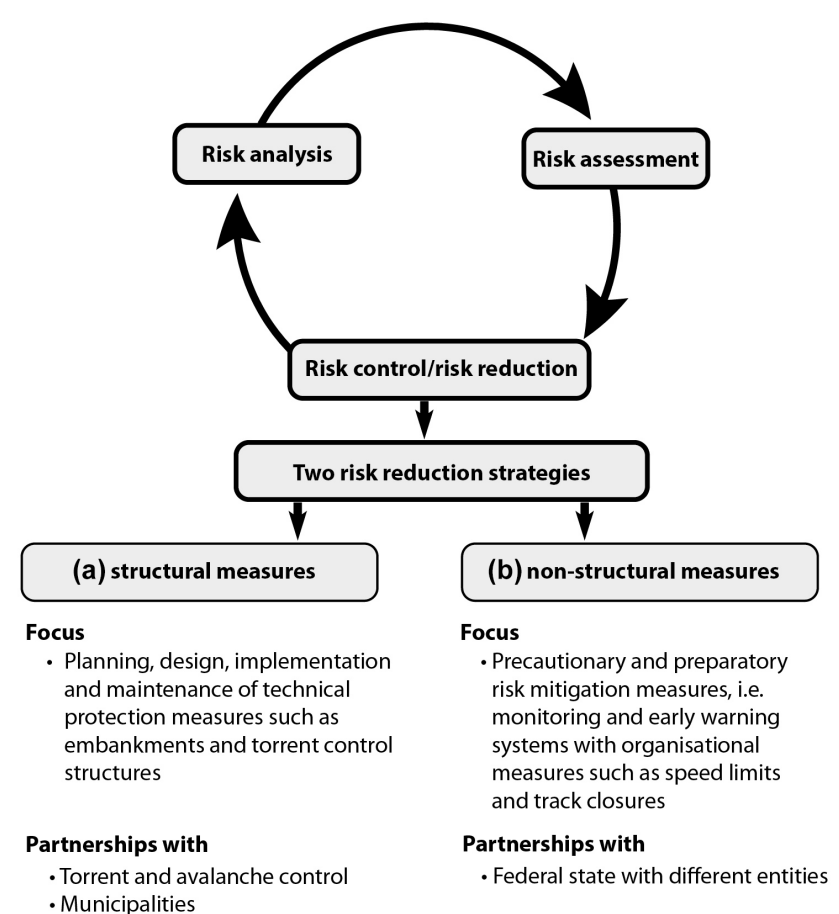

Figure 1. Risk management cycle and strategies of the ÖBB.

Kellermann et al. (2015) aimed at closing the gap of more targeted flood risk analyses for the railway transportation sector by developing a flood damage model for the estimation of both structural damage to railway infrastructure and incurred direct economic losses, i.e. repair costs. This model, named RAilway Infrastructure Loss (RAIL), was derived from empirical, i.e. photo-documented, flood damage data collected during and after the Morava River flood in Lower Austria in 2006. The model RAIL is capable of estimating (1) the expected structural damage for the standard cross section of railway tracks using water depths as a basis and (2) resulting repair costs. This two-step approach allows us to estimate not only direct economic loss, which is a widespread research practice, but also structural damage types. The latter capacity of the RAIL model enables the user to obtain new information on the occurrence of specific grades of structural flood damage at individual track segments and, hence, to identify potential hot spots of flood risk at railway tracks and to support the decision-making with regard to flood risk management tasks, e.g. the strategic planning and prioritization of technical protection measures. A similar approach was implemented by Maiwald and Schwarz (2014a, b) for residential buildings damaged by river floods. A comparative study of methods to assess the physical vulnerability of structures is given in Papathoma-Köhle (2016).

So far, a large-scale estimation of flood damage explicitly to railway infrastructure is still missing, since both appropriate flood damage models and suitable exposure data were lacking. However, such risk information is needed for com- 


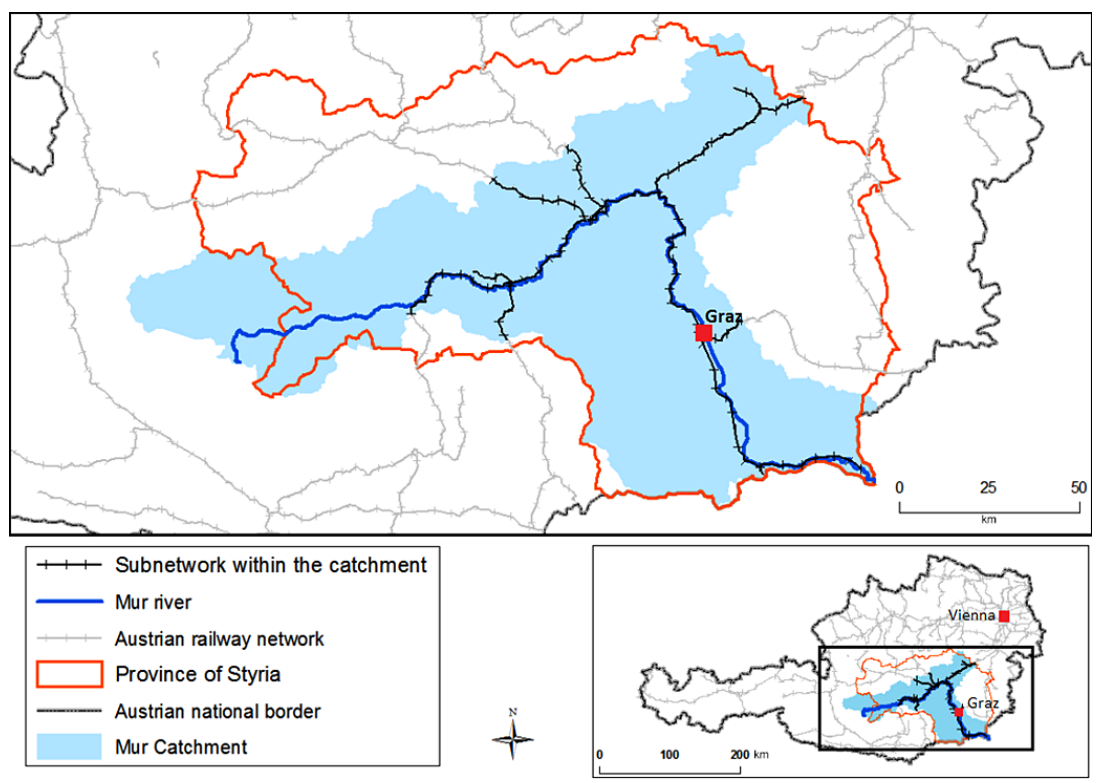

Figure 2. Location of the Mur catchment and the railway network under consideration.

prehensive flood risk assessment, as well as for support of the decision-making within railway operations management. The objective of the study at hand was to fill this research gap. Thus, the RAIL model was applied to the Austrian railway subnetwork located in the Mur River catchment and the model uncertainties of RAIL were investigated by analysing the sensitivity of the model results to the modification of the key assumptions in the model framework. In a subsequent step, three different degrees of risk aversion of the ÖBB were assumed and implemented in the calculation of the expected annual flood damage in order to investigate its impact in the risk quantification. In the context of natural risk management, the term "risk aversion" indicates the aversion of the railway operator (or also the general public) towards catastrophes and distress (BABS, 2003). Accordingly, the implementation of risk aversion in the risk quantification of flood risk for railway infrastructure allows putting special emphasis on the ultimate premise of the ÖBB to ensure safety of passengers and personnel (see Eisenbahngesetz §19b, 2016). Finally, since climate change might have a certain impact on future flood risk in Austria and, hence, relativize the risk information obtained in this study, related research findings were briefly evaluated. In doing so, we aim at obtaining indications on the sustainability of the current flood risk characterization as well as respective management approaches.

\section{Data and methods}

\subsection{The Mur River catchment}

The Mur River catchment was selected as an application area for the RAIL model due to (1) availability of both digital ele- vation model and hydraulic simulation data, (2) an appropriate spatial scale for a large-scale test approach and (3) the significant importance of the regional infrastructure subnetwork for the ÖBB railway service (see Sect. 2.4). The Mur River is the main river of the province of Styria located in southern Austria (see Fig. 2). Originating in the Salzburg Alps, the Mur runs through the province of Styria and its capital Graz, crosses the borders to Slovenia, Croatia and Hungary and empties into the Drau River after a total water course length of approx. $453 \mathrm{~km}$ (thereof approx. $350 \mathrm{~km}$ in Austria) (Fartek et al., 2001). Draining an area of approx. $10340 \mathrm{~km}^{2}$ of Austrian national territory, the average flow of the Mur at the gauge Mureck is $147 \mathrm{~m}^{3} \mathrm{~s}^{-1}$ and the highest ever measured flow reached $1251 \mathrm{~m}^{3} \mathrm{~s}^{-1}$ in August 2005, which corresponds approximately to a 10-year flood event (BMLFUW, 2013). The flow of a 100-year flood event was estimated to $1800 \mathrm{~m}^{3} \mathrm{~s}^{-1}$ (Fartek et al., 2001).

\subsection{The RAIL model}

The flood damage model RAIL was empirically derived from the Morava River flood event in 2006 at the Austrian Northern Railway and designed to estimate both structural damage at a railway track's standard cross section and the resulting repair costs (see Sect. 1). A railway track's standard cross section consists of the elements substructure, superstructure, catenary and signals. Depending on the water level at exposed track sections, different degrees of structural flood damage can be expected at one (or more) of those elements. In order to estimate these, the RAIL model distinguishes three structural damage classes. The classes are designed for the purpose of fast and practical in-field damage assessments and scaled ordinally (Kellermann et al., 2015). In damage 
class 1, the track's substructure is (partly) impounded, but no or only little notable damage is expected. When being classified as damage class 2 , the substructure and superstructure of the affected track section is fully inundated and significant structural damage at least to the substructure must be expected. Consequently, additional damage to the superstructure, catenary and/or signals is expected in damage class 3 and, hence, the standard cross section of the affected track section is assumed to be completely restored.

For the estimation of the financial losses due to the repair of damaged track sections, the following standard costs were considered (Kellermann et al., 2015): (1) costs of loss assessment/documentation, (2) cost for track cleaning per running metre (rm) and (3) standard cross section repair costs per rm as defined by Austrian railway infrastructure experts (BMLFUW, 2008). These three cost types were individually combined for each damage class according to the corresponding structural damage pattern. Therefore, the standard repair costs for a damage class 1 amount to EUR 11700 , the costs for damage class 2 are EUR 135550 and the costs for damage class 3 total EUR 702 200, whereby all values refer to a $100 \mathrm{~m}$ section of a double-tracked railway line. For singletracked railway lines, these values have to be adapted.

The substructure is the most expensive element of a railway standard cross section and, hence, has a notably high weight within the estimation of repair costs. Therefore, the damage grade of a damaged substructure can significantly bias the loss estimation, since the defined standard repair costs only consider a full restoration providing no further graduation of costs for minor repairs (e.g. tamping of the substructure). However, since it is not assured that a full restoration of the substructure is required when a track section is classified as damage class 2, the loss estimates had to be calibrated (Kellermann et al., 2015). Hence, a proportional factor for damage to the substructure in damage class 2 was determined on the basis of the empirical damage data of the Morava River flood in 2006. This approach resulted in a cost calibration factor for damage class 2 amounting to 0.25 . More detailed information on the RAIL model can be found in Kellermann et al. (2015).

\subsection{Exposure analysis}

Comprehensive flood hazard information, i.e. area-wide data on water depths at affected track sections, is required to apply the RAIL model at the catchment scale. In the framework of the implementation of the European Floods Directive (European Union, 2007, Directive 2007/60/EC), a series of flood hazard maps that basically meet those data requirements were produced for Austria. More detailed information on Austria's flood hazard maps can be found in BMLFUW (2015). The maps are also publicly accessible via the web-GIS tools Wasserinformationssystem Austria (WISA) (http://wisa.bmlfuw.gv.at).
However, the flood hazard maps are not sufficient as input data for the RAIL model for two reasons. First, the flood hazard maps are produced on a spatial scale of $1: 25000$. This scale is seen as being inadequate to provide detailed spatial information on linear structures such as railway lines. Second, the flood hazard maps feature a rather low information level with respect to water depths, since this decisive flood impact parameter is only provided on the basis of three categories of water depths, i.e. $<0.6,0.6-1.5$ and $>1.5 \mathrm{~m}$. Using this classification for water depths, it is not possible for the RAIL model to determine the resulting structural damage class at affected track segments unambiguously.

However, to achieve an appropriate level of detail for issuing targeted flood warnings for the railway service and for analysing flood risks in the railway infrastructure network, the ÖBB planned to reanalyse and improve the available flood hazard information by the following approach: first, taking the Austrian flood hazard maps as reference, an exposure analysis was performed by superimposing the Austrian railway network with the designated inundation areas for flood return periods of 30, 100 and 300 years using a GIS. Thereby the network is subdivided into track sections of a length of $100 \mathrm{~m}$ each, which follows the standard distances between the waypoints along a railway track (i.e. the chainage) and, hence, is in accordance with the standard dimensioning approach used in railway infrastructure planning and design. In a second step, the degree of potential affectedness of the exposed track sections was further analysed by determining the height difference of the altitude of the top edge of the relevant track section and the water level line the so-called freeboard. However, since the Austrian flood hazard maps are inappropriate for this purpose due to the coarse vertical resolution of water depths, a set of hydraulic simulations delivering an appropriate vertical resolution of water depths was used by the ÖBB to calculate the freeboard values.

On the basis of the exposure analysis approach described above, the degree of potential affectedness of the regional railway subnetwork (i.e. the freeboard) was determined for exposed track sections. Since the freeboard values each represent a $100 \mathrm{~m}$ track section, they are in accordance with the design of the RAIL model, which uses the same track section length as a spatial reference for flood damage estimates.

\subsection{Damage estimation}

In order to estimate structural flood damage to railway infrastructure and resulting repair costs for a 30-, 100- and 300year flood in the Mur catchment, the RAIL model developed by Kellermann et al. (2015) was applied (see Sect. 1). Therefore, the freeboard values derived from of the ÖBB exposure analysis (see Sect. 2.3) were considered as input. However, the RAIL model uses absolute water depths to estimate structural flood damages to the rail track (Kellermann et al., 2015). Hence, since the freeboard values only give a relative indica- 
tion of the hazard potential and provide no absolute values of water depths and since the original hydraulic simulations were not provided for use in this study, the data had to be converted accordingly. For this purpose, due to the necessity of determining the absolute construction height of the affected track sections referring to the ground level and due to the fact that no elevation profiles were accessible, assumptions had to be made about the standard construction characteristics of the railway subnetwork in the Mur catchment. A rail track consists of two major structures: the substructure and the superstructure. According to the ÖBB technical code for conventional track systems in Austria, the standard construction height for the superstructure is $50 \mathrm{~cm}$. For the construction height of the substructure, however, no standard is defined, since this parameter is dependent on a variety of local terrain characteristics such as soil bearing capacity and ground inclination (Rahn, 2007). For example, on soils having a low loadbearing capacity, the construction height of the rail track's substructure must be kept low to avoid structural instabilities. With increasing ground inclinations, however, the height of the substructure must necessarily increase in order to obtain an inclination-free track layout. As a general principle and not least to save bulk material and thus costs, the height of the substructure (or rail embankment) should be kept as low as possible. According to Rahn (2007), a common construction height in a lowland area with an average soil bearing capacity is in the range of $1 \mathrm{~m}$. Considering the standard construction heights of both the substructure (i.e. $1 \mathrm{~m}$ ) and the superstructure (i.e. $50 \mathrm{~cm}$ ) as constantly given in the study area, we used the resulting total construction height of the railway subnetwork of $1.5 \mathrm{~m}$ as a basis for the conversion of freeboard values into absolute water depths.

First, the derived water depths were fed into the RAIL model and both the structural damage and the resulting repair costs (or direct economic loss) caused by the given flood scenarios were estimated for the entire railway subnetwork situated in the Mur catchment. The estimated structural damage classes were then cartographically mapped and the repair costs were used to calculate the expected annual damage (EAD), which is a common risk metric (Merz et al., 2009). The EAD is defined as the average monetary loss that is to be statistically expected each year and is estimated on the basis of selected discrete hazard scenarios with different probabilities. It is calculated as follows (Merz et al., 2009):

$\mathrm{EAD}=\sum_{j=1}^{m} \Delta P_{j} D_{j}$,

where $D_{j}$ and $P_{j}$ are the average flood damage and the exceedance probability increment for the $j$ th interval, respectively, and $m$ is the number of probability increments (Merz et al., 2009):

$D_{j}=\frac{1}{2}\left(D\left(h_{j}\right)+D\left(h_{j+1}\right)\right)$,

$\Delta P_{j}=P\left(h_{j}\right)-P\left(h_{j+1}\right)$.
Since the EAD has been criticized for underrepresenting extreme events (see Merz et al., 2009), risk aversion is considered as described in Sect. 2.6.

In a second step, the RAIL model was separately applied to five predefined operational sections within the subnetwork and the individual EAD values were recalculated in order to provide more targeted risk information. Those operational sections were selected by consideration of important network junctions and marked out by major rail stations with in the Mur catchment railway subnetwork. To assess the relative importance of operational sections, the number of trains running on each section was used as an indicator. Therefore, the track utilization figures of 2013 for the ÖBB railway network serves as a basis. The data contain the daily mean number of trains running on each operational section, whereby all types of train used in Austria (e.g. regional trains, express trains, freight trains) are considered. By sorting the numbers in descending order, a ranking of the importance of the operational sections within the study area was established. Hence, the operational section with the highest volume of train traffic in 2013 was classified as the most important one. The resulting ranking of importance of operational sections was then compared to the ranking resulting from their individual EAD values in order to identify potential lacks of prioritization in the implementation of risk reduction measures.

\subsection{Sensitivity analysis}

The flood damage model RAIL implies two key assumptions in the model application, namely (1) the constant construction height of the substructure of $1 \mathrm{~m}$ (see Sect. 2.4) and (2) the cost calibration factor of 0.25 for the loss estimates referring to damage class 2 (see Sect. 2.2 and Kellermann et al., 2015). Since these simplifications may involve significant model uncertainties and, hence, lead to potential misinterpretations, the sensitivity of the model results was analysed. For this, both factors of uncertainty were modified based on two variants: modification variant A stands for the "best case" variant, where the assumed standard construction height of the substructure was increased from 1 to $1.2 \mathrm{~m}$ and the cost calibration factor was decreased from 0.25 to 0.2 . In modification variant $\mathrm{B}$, the substructure height was decreased from 1 to $0.8 \mathrm{~m}$ and the cost calibration factor was increased from 0.25 to 0.3 , which is equivalent to a "worst case" model variant. The EAD was recalculated on the basis of each variant and resulting values were compared in order to assess the appearing variances.

\subsection{The aspect of risk aversion}

According to BABS (2003), one natural event causing devastating damage and loss is much more strongly perceived and evaluated by the general public than numerous events causing, in total, the same amount of damage, while the damage of each event is comparatively small. Against the back- 


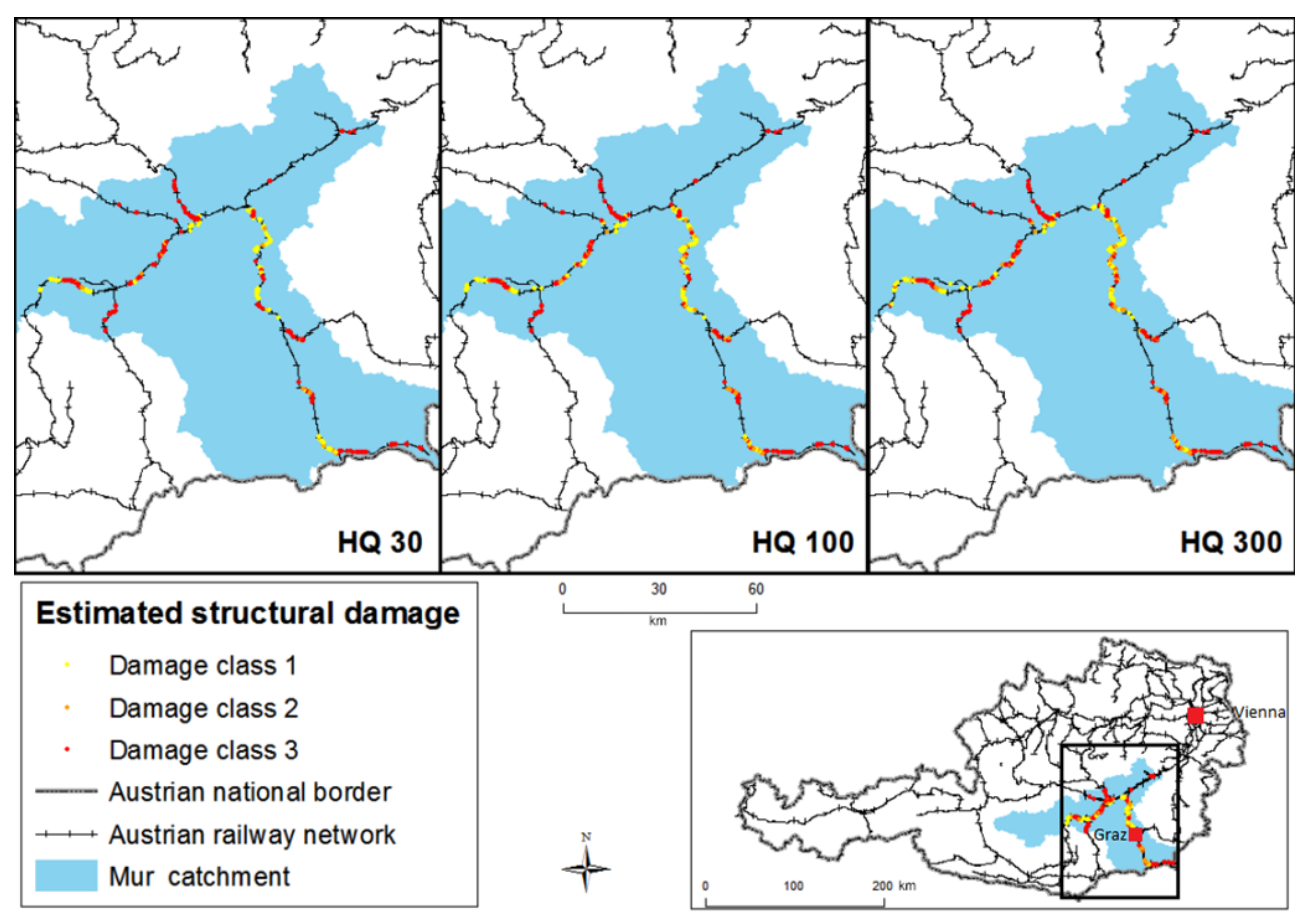

Figure 3. Estimation of damage potentials. The map shows the RAIL model results for synthetic flood events of return periods of 30 years (left), 100 years (middle) and 300 years (right).

ground that the ultimate premise of the railway operator is to ensure safety of passengers and personnel and, hence, to prevent people being exposed to natural hazards (Thieken et al., 2013), different degrees of risk aversion were assumed and implemented in the calculation of the EAD in order to investigate its impact on the risk quantification.

In accordance with BABS (2003), three different risk aversion factors, i.e. 10,50 and 100 , were added as weighting factors to the computation of the share of EAD of the lowprobability events (HQ100-HQ300). Expressed mathematically, the solution of the variable $D_{j}$ for $\Delta P_{j}=0.0067$ (see Eqs. 2 and 3) was separately multiplied with each risk aversion factor and the EAD was recalculated (see Eq. 1).

\section{Results}

\subsection{Damage and loss on the catchment scale}

In a first step, the potential damage and loss of the Austrian railway subnetwork within the Mur catchment were investigated. Using the derived water depths as input (see Sect. 2.3 and 2.4), the RAIL model was applied to produce scenariobased estimates of the structural damage at flood-affected track sections as well as direct monetary losses in terms of repair costs. The model estimates on structural damage are mapped in Fig. 3 showing the classified damage for each $100 \mathrm{~m}$ track section. The maps indicate that significant damage has to be expected not only for long stretches along the course of the Mur River (see Figs. 2 and 3) but also at track sections being located adjacent to certain tributaries: for example, it is estimated that the Liesing River flowing into the Mur River in the north of the study area also causes extensive damage, i.e. in most cases classified as damage class 3 , already on the basis of a 30-year flood scenario. The flood damage maps furthermore reveal that both the number of affected track sections and the share of higher damage classes increase with decreasing flood event probability.

The total number of potentially damaged track sections per damage class and per flood scenario as well as resulting repair cost estimates are given in Table 1. It is striking that the proportion of track sections classified as damage class 3 is very high already for the 30 -year flood scenario. This ratio changes only slightly with decreasing event probability, since the increase in the number of track sections classified as damage class 1 or 2 then outweighs the increase in the damage class 3 . However, the absolute number of affected track sections classified as damage class 3 remains the highest in all scenarios.

The large proportion of track sections encountering heavy structural damage is also reflected in the resulting repair costs of the infrastructure, since the overall costs of damage class 3 for all flood scenarios account for more than $93 \%$ (see Table 1). Considering the available scenario bandwidth (HQ30-HQ300) for this RAIL application, the EAD for the entire railway subnetwork amounts to EUR 8780000 (rounded to three significant digits), wherein the loss propor- 
Table 1. Estimated number of damaged track sections per damage class and per flood scenario as well as related repair costs on the Mur catchment level. The EAD is rounded to three significant digits.

\begin{tabular}{|c|c|c|c|c|c|}
\hline & Damage class 1 & Damage class 2 & Damage class 3 & Total & \\
\hline No. of affected sections & 175 & 36 & 364 & 575 & \multirow{2}{*}{ HQ 30} \\
\hline Repair costs & EUR 2047500 & EUR 4879800 & EUR 255600800 & EUR 262528100 & \\
\hline No. of affected sections & 297 & 118 & 404 & 819 & \multirow{2}{*}{ HQ 100} \\
\hline Repair costs & EUR 3474900 & EUR 15994900 & EUR 283688800 & EUR 303158600 & \\
\hline No. of affected sections & 321 & 183 & 457 & 961 & \multirow{2}{*}{ HQ 300} \\
\hline Repair costs & EUR 3755700 & EUR 24805650 & EUR 320905400 & EUR 349466750 & \\
\hline EAD & & & & EUR 8780000 & \\
\hline
\end{tabular}

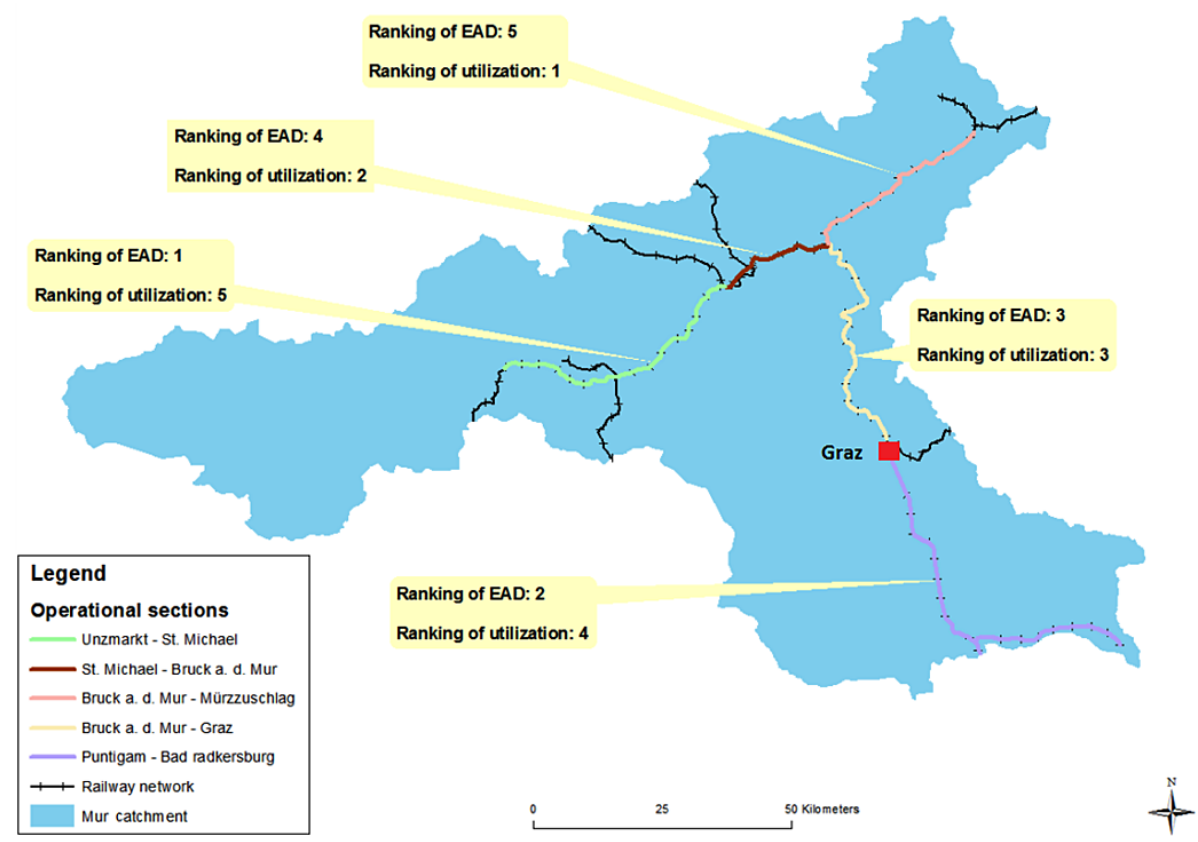

Figure 4. Operational sections of the railway subnetwork. The yellow boxes provide the individual rankings according to the EAD value and the track utilization figure of 2013.

tion of the low-probability events (HQ100-HQ300) equals to 25 and $75 \%$ for the high-/medium-probability events (HQ30-HQ100). Accordingly, the share of three-quarters of high-/medium-probability events in the EAD corroborates the results obtained from the flood damage maps which also demonstrate a high (structural) damage potential for this event intensity.

\subsection{Damage and loss on the operational level}

With the aim of providing more targeted information on the risk potentials, the railway network under study was further differentiated into operational sections by means of important network junctions as well as major rail stations (see Sect. 2.4). Figure 4 shows the five operational sections identified by these two selection criteria. It has to be noted that, as indicated in the map, some parts of the network (e.g. two sections in the north of the study area) are no longer taken into consideration in this step of the analysis, since either (at least) one selection criterion is not fulfilled or the operational section is not entirely located within the catchment area. After the identification of important operational sections, the EAD values were calculated for each section.

The change of the investigation level leads to more detailed insights regarding the shares of structural damage classes as well as the distribution of losses within the railway subnetwork (see Table 2). First, it emerged that the large proportion of damage class 3 identified on the network level does not apply to all operational sections. In particular, the section Bruck a.d. Mur - Graz particularly shows segments that are classified as damage class 1 (i.e. with no or only little notable structural damage), whereas the damage classes 2 
Table 2. Flood damage estimation on the level of selected operational sections. The table furthermore provides the individual rankings according to the EAD (expected annual damage) as well as the track utilization figure of 2013.

\begin{tabular}{|c|c|c|c|c|c|c|c|c|}
\hline & & $\begin{array}{l}\text { Damage } \\
\text { class } 1\end{array}$ & $\begin{array}{l}\text { Damage } \\
\text { class } 2\end{array}$ & $\begin{array}{l}\text { Damage } \\
\text { class } 3\end{array}$ & Total & $\begin{array}{l}\text { Flood } \\
\text { scenario }\end{array}$ & $\begin{array}{c}\text { Rank of } \\
\text { EAD }\end{array}$ & $\begin{array}{c}\text { Rank of } \\
\text { utilization }\end{array}$ \\
\hline \multirow{7}{*}{ 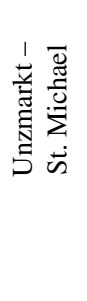 } & No. of affected sections & 31 & 16 & 112 & 159 & \multirow[t]{2}{*}{ HQ 30} & \multirow{7}{*}{1} & \multirow{7}{*}{5} \\
\hline & Repair costs & EUR 362700 & EUR 2,168,800 & EUR 78646400 & EUR 81177900 & & & \\
\hline & No. of affected sections & 59 & 38 & 123 & 220 & \multirow{2}{*}{ HQ 100} & & \\
\hline & Repair costs & EUR 690300 & EUR 5,150,900 & EUR 86370600 & EUR 92211800 & & & \\
\hline & No. of affected sections & 56 & 56 & 140 & 252 & \multirow{2}{*}{ HQ 300} & & \\
\hline & Repair costs & EUR 655200 & EUR 7,590,800 & EUR 98308000 & EUR 106554000 & & & \\
\hline & EAD & & & & EUR 2690000 & & & \\
\hline \multirow{7}{*}{ 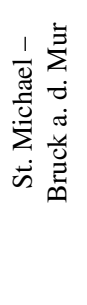 } & No. of affected sections & 1 & 0 & 7 & 8 & HQ 30 & \multirow{7}{*}{4} & \multirow{7}{*}{2} \\
\hline & Repair costs & EUR $11 / 00$ & EUKO & EUR 4915400 & EUR 4927100 & & & \\
\hline & No. of affected sections & 2 & 0 & 8 & 10 & $\mathrm{HO} 100$ & & \\
\hline & Repair costs & EUR 23400 & EUR 0 & EUR 5617600 & EUR 5641000 & HQ 100 & & \\
\hline & No. of affected sections & 6 & 1 & 9 & 16 & $\mathrm{HO} 300$ & & \\
\hline & Repair costs & EUR 70200 & EUR 135550 & EUR 6319800 & EUR 6525550 & HQ 300 & & \\
\hline & EAD & & & & EUR 164000 & & & \\
\hline \multirow{7}{*}{ 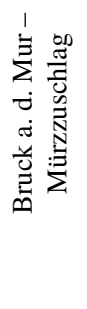 } & No. of affected sections & 0 & 0 & 5 & 5 & $\mathrm{HO} 30$ & \multirow{7}{*}{5} & \multirow{7}{*}{1} \\
\hline & Repair costs & EUR 0 & EUR 0 & EUR 3511000 & EUR 3511000 & חए & & \\
\hline & No. of affected sections & 0 & 0 & 5 & 5 & $\mathrm{HO} 100$ & & \\
\hline & Repair costs & EUR 0 & EUR 0 & EUR 3511000 & EUR 3511000 & He 100 & & \\
\hline & No. of affected sections & 0 & 0 & 7 & 7 & $\mathrm{HO} 300$ & & \\
\hline & Repair costs & EUR 0 & EUR 0 & EUR 4915400 & EUR 4915400 & חर 300 & & \\
\hline & EAD & & & & EUR 110000 & & & \\
\hline \multirow{7}{*}{ 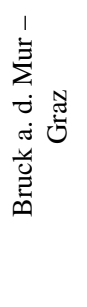 } & No. of affected sections & 93 & 3 & 30 & 126 & \multirow{2}{*}{ HQ 30} & \multirow{7}{*}{3} & \multirow{7}{*}{3} \\
\hline & Repair costs & EUR 1088100 & EUR 406650 & EUR 21066000 & EUR 22560750 & & & \\
\hline & No. of affected sections & 167 & 26 & 44 & 237 & \multirow{2}{*}{ HQ 100} & & \\
\hline & Repair costs & EUR 1953900 & EUR 3524300 & EUR 30896800 & EUR 36375000 & & & \\
\hline & No. of affected sections & 190 & 49 & 61 & 300 & \multirow{2}{*}{ HQ 300} & & \\
\hline & Repair costs & EUR 2223000 & EUR 6641950 & EUR 42834200 & EUR 51699150 & & & \\
\hline & EAD & & & & EUR 981000 & & & \\
\hline \multirow{7}{*}{ 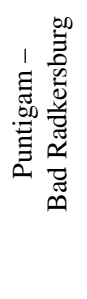 } & No. of affected sections & 30 & 14 & 96 & 140 & & \multirow{7}{*}{2} & \multirow{7}{*}{4} \\
\hline & Repair costs & EUR 351000 & EUR 1897700 & EUR 67411200 & EUR 69659900 & HQ 30 & & \\
\hline & No. of affected sections & 25 & 45 & 108 & 178 & \multirow{2}{*}{ HQ 100} & & \\
\hline & Repair costs & EUR 292500 & EUR 6099750 & EUR 75837600 & EUR 82229850 & & & \\
\hline & No. of affected sections & 32 & 49 & 115 & 196 & \multirow{2}{*}{ HQ 300} & & \\
\hline & Repair costs & EUR 374400 & EUR 6641950 & EUR 80753000 & EUR 87769350 & & & \\
\hline & EAD & & & & EUR 2340000 & & & \\
\hline
\end{tabular}

and 3 occur relatively seldom. However, the opposite can also be found: the section Bruck a.d. Mur - Mürzzuschlag shows no damage meeting the criteria for damage classes 1 and 2 for all scenarios and only track sections exhibiting damage class 3 (see Table 2). The largely differing structural damage patterns are also reflected in the individual EAD values, ranging from EUR 110000 to 2690000 per year (rounded to three significant digits).

A further objective of this study was to investigate the potential need for action in terms of risk reduction measures by comparison of the grade of track utilization of individual operational sections and their specific risk potential (see Sect. 2.4). Therefore, the operational sections were ranked (1) on the basis of their individual train numbers of 2013 and (2) on the basis of their EAD values. The resulting ranking is depicted both in Table 2 and Fig. 4. Interestingly, the comparison shows that the ranking of EADs is ordered mirrorinverted to the ranking of track utilization. Hence, for example, the operational section Unzmarkt - St. Michael is ranked first with respect to its EAD value and shows the lowest 
Table 3. Expected annual damage for different model settings. Modification variant A comprises of an assumed substructure height of $1.2 \mathrm{~m}$ and a cost calibration factor of 0.2. Modification Variant B comprises of an assumed substructure height of $0.8 \mathrm{~m}$ and a cost calibration factor of 0.3. All values are rounded to three significant digits.

\begin{tabular}{llll}
\hline & \multicolumn{3}{c}{ Expected annual damage } \\
\cline { 2 - 4 } & Modification A & Default settings & Modification B \\
\hline St. Michael - Unzmarkt & EUR 2 590000 & EUR 2 690000 & EUR 2 850 000 \\
Bruck a.d. Mur - St. Michael & EUR 164000 & EUR 164 000 & EUR 164 000 \\
Bruck a.d. Mur - Mürzzuschlag & EUR 110000 & EUR 110 000 & EUR 110 000 \\
Bruck a.d. Mur - Graz & EUR 919000 & EUR 981 000 & EUR 1 080 000 \\
Puntigam - Bad Radkersburg & EUR 2 210000 & EUR 2340000 & EUR 2 490000 \\
\hline
\end{tabular}

Table 4. Expected annual damage for operational sections and for varying risk aversion factors.

\begin{tabular}{lllll}
\hline \multirow{2}{*}{ Operational section } & \multicolumn{4}{c}{ Expected annual damage } \\
\cline { 2 - 5 } & & Default settings & \multicolumn{3}{c}{ Risk aversion factor } \\
\cline { 3 - 5 } & & 10 & 50 & 100 \\
\hline St. Michael - Unzmarkt & EUR 2 690 000 & EUR 8 600 000 & EUR 35 200 000 & EUR 68 300 000 \\
Bruck a.d. Mur - St. Michael & EUR 164000 & EUR 500 000 & EUR 2 160000 & EUR 4 200 000 \\
Bruck a.d. Mur - Mürzzuschlag & EUR 110000 & EUR 400 000 & EUR 1 500 000 & EUR 2 900 000 \\
Bruck a.d. Mur - Graz & EUR 981 000 & EUR 3 100 000 & EUR 15 400 000 & EUR 25 200 000 \\
Puntigam - Bad Radkersburg & EUR 2 340 000 & EUR 7 400 000 & EUR 30 100 000 & EUR 58 400 000 \\
\hline
\end{tabular}

rank with respect to the track utilization, whereas the section showing the highest rank of utilization, i.e. the section St. Michael - Bruck a.d. Mur, is ranked last in terms of its EAD value.

\subsection{Sensitivity of RAIL estimates}

In order to get insights in the sensitivity of the RAIL estimates, the two key assumptions for the model application were modified in two different variants and, subsequently, the EADs of the operational sections were recalculated (see Sect. 2.5). The resulting values of both variants and, in order to facilitate the comparison, also the EAD values resulting from the original model assumptions are depicted in Table 3. The application of variant $\mathrm{A}$, i.e. the increase in the assumed standard construction height of the substructure from 1 to $1.2 \mathrm{~m}$ along with the decrease in the cost calibration factor for damage class 2 from 0.25 to 0.2 (see Sect. 2.5), led to a reduced EAD in most cases. Conversely, the modification of the key model assumptions towards more unfavourable preconditions, i.e. a decrease in the standard construction height from 1 to $0.8 \mathrm{~m}$ along with an increase in the cost calibration factor for damage class 2 from 0.25 to 0.3 , results in augmented EAD values. However, there are two exceptions, namely the operational sections "Bruck a.d. Mur - St. Michael" and "Bruck a.d. Mur - Mürzzuschlag", for which the modifications show no effect and can thus be regarded as rather robust. In general, the comparison of the EAD resulting from the modifications with the default EAD values reveals no marked deviations ranging from approx. 4 to approx. $10 \%$ in relative terms and from EUR 99000 to 160000 in absolute terms. Accordingly, the apparent low sensitivity of results indicates a robust estimation of flood damage by the RAIL model, at least in this study area.

\subsection{Impacts of risk aversion}

In a final step of the study, the impact of risk aversion on the estimation of flood risks was investigated in order to put special emphasis on the ultimate premise of the ÖBB to ensure safety of passengers and personnel. In detail, three different risk aversion factors were implemented in the calculation of the EAD values, whereby only the lower-probability events, i.e. the HQ100-HQ300 scenario bandwidth, were of relevance (see Sect. 2.6). Table 4 presents the results for all risk aversion factors. It can be seen that the consideration of risk aversion against low-probability (or high impact) events by adding a weighting factor leads to an extensively increased EAD value for all operational sections within the Mur catchment. In detail, the risk aversion factor 10 already caused an increase of more than 3 times the default value, whereas the factor 50 even brought an increase of more than 10-fold, and the factor 100 led an the increase in the EAD value of well over 25 times the default value. In view of the fact that the HQ100-HQ300 scenario bandwidth accounts for a proportion of only $25 \%$ of the EAD on average (see Sect. 3.1), the consistently large increases underline the considerable influence of the aspect of risk aversion on flood risk estimates for 
the study area, in particular with regard to the development of risk management strategies.

\section{Discussion}

In this study, flood damage to railway infrastructure was estimated on the large scale (i.e. the catchment level) with the objective of obtaining new flood risk information for railway infrastructure and, consequently, supporting strategic planning and decision-making of the ÖBB with regard to structural protection measures. For this, both the structural damage and resulting repair costs were estimated for the railway subnetwork located in the Mur catchment on two different spatial scales, i.e. the catchment level and the operational level, using the flood damage model RAIL. As a further goal, the sensitivity of estimates of the economic flood loss as provided by the EAD was analysed by a modification of the key model assumptions. Three different degrees of risk aversion were furthermore implemented in the calculation of the EAD in order to investigate its impact on the flood damage estimates in the study area and, hence, on the potential decisionmaking in a risk management context.

Different aspects of the achieved results are discussed in this section. First, the limitations of the flood damage model RAIL and associated uncertainties are reflected in order to allow a sound interpretation and evaluation of the results presented thereafter. Accordingly, the potential benefits for a railway operator from the given information basis are portrayed and recommendations for action are outlined next. Finally, the achieved risk information is briefly discussed against the background of climate change and possibly resulting changes in flood risk.

\subsection{Model limitations and uncertainties}

In general, the case study demonstrates that the RAIL model can be applied to estimate flood damage to railway infrastructure in larger areas (e.g. river catchments, national territories). This can be done if the following conditions are met: (1) the general construction characteristics of the railway infrastructure must be the same as (or very similar to) the characteristics of the Northern Railway, on the basis of which the RAIL model was derived (Kellermann et al., 2015). Accordingly, slab tracks (i.e. high-speed railway lines), for example, are not suitable to be investigated by RAIL without amendments since their construction design is significantly different from the design of the Northern Railway line and, hence, the derived correlations of flood impact and resulting damage would be no longer valid. Different empirical data would be needed to adapt the RAIL model to such types of railway tracks. (2) The RAIL model was derived from flood impacts caused by rather low flow velocities, i.e. river floods occurring in flat areas, which was the case at the Morava River flood in Lower Austria in 2006. However, around $65 \%$ of
Austria is located in Alpine areas mainly characterized by high relief energy and steep slopes. In such topography, fluvial natural events often show hydraulic characteristics being significantly different to river flooding, in particular with regard to the flow velocity. Accordingly, since the RAIL model has not yet been tested for varying flood types, it is assumed that the RAIL model is in a first instance valid for lowland rivers and, hence, might be limited in estimating flood damage on the national level of a country like Austria providing a high topographic complexity (Kellermann et al., 2015). Indeed, the Mur catchment also features considerable portions of land with complex topography - first and foremost in the western part of the catchment area - and, hence, may obviously introduce uncertainties in the RAIL model estimates. Therefore, the robustness of the model results was tested.

The main model uncertainties of RAIL lie in the two key assumptions made within the model design, which are (1) the construction height of the railway substructure and (2) the cost calibration factor for the estimation of economic loss linked to damage class 2 (see Sect. 2.5 and 3.3). The first assumption had to be made in order to convert the available impact data, i.e. the freeboard values, from relative water levels to absolute water depths being the required input data format for the RAIL model. It can be assumed that fixing the construction height to a constant value involves uncertainties, since in reality the substructure height can vary significantly within larger areas, in particular in complex topographic areas. The second assumption rests on the empirical damage data of the Morava flood event in 2006 at the Austrian Northern Railway. In principle, this empirical factor represents the average of observed damage to the substructure of the Northern Railway (Kellermann et al., 2015). However, it may change for different study areas due to e.g. changing flood event or rail track construction characteristics and, thus, may also entail epistemic uncertainty. In order to analyse the potential impact of the uncertainties described above, the sensitivity of results was investigated by modifying the key model assumptions. Results show that the modifications only lead to marginal variations of the estimates and, hence, suggest a certain degree of robustness (see Sect. 3.3). A closer look at the results further reveals that the construction height of the substructure has an overall higher influence on the loss estimates in comparison to the cost calibration coefficient, which, on the one hand, confirms that assuming a fixed construction height might considerably bias the results and, on the other hand, endorses the practicality of the cost calibration factor. It should be noted though that the presented sensitivities of results can only be presumed as being valid for the study area at hand, since the individual impact of all factors of uncertainty may change markedly in other study areas. For example, the damage class 2 may be better represented in other large-scale damage patterns and, hence, the influence of the calibration coefficient could increase substantially. 
Initially, the RAIL model was derived on the basis of preliminary work of Moran et al. (2010a), who distinguished between five different structural damage classes to estimate the degree of flood damage for exposed track sections. The (statistical) results, however, were not satisfactory on the basis of such a detailed classification. Hence, after discussing and evaluating the initial results with railway experts, we revised the classification of Moran et al. (2010a) and reduced the number of categories from five to three with the aim of focussing on structural damage to the substructure as the most important and expensive element of the standard cross section. This approach led to a marked increase in the statistical correlations of flood impact and structural damage and, furthermore, confirms the supposition that a finer classification of structural (and economic) damage is not required, since from the engineering perspective there is no significant difference between certain grades of damage to the track, e.g. minor, medium and major erosion damage to the substructure. In case the railway track's substructure is (at least somehow) damaged, the train service is disrupted and the segment has to be repaired.

The uncertainty entailed by a fixed construction height of a substructure could theoretically be removed by revising the model approach. Hence, instead of using absolute water depths as the decisive flood impact parameter, the RAIL model could be newly derived on the basis of relative water levels. However, impact data providing freeboard values of railway infrastructure for a given flood scenario are usually not available, for which the scope of application of the RAIL model in practice would be very limited. It is therefore appropriate to initially strive for a validation of the RAIL model in order to clarify its performance in different areas. This would require a better and comprehensive documentation of damaging flood events.

Additionally, flood damage should also be estimated for more dynamic flood events and subsequently validated on the basis of documented damage in order to obtain targeted performance indicators of the damage model for higher flow velocities. Due to data scarcity, however, this validation tasks could not yet be implemented.

\subsection{Insights for railway operation and natural hazard management}

A particular added value of the RAIL model is seen in its two-step modelling approach, i.e. the estimation of both, structural damage at exposed track sections and resulting repair costs. The estimation of structural damage is usually neglected in existing flood damage models, i.e. only (relative or absolute) monetary losses are computed. However, the localization of significant structural damage potentials at specific track sections coupled with the identification of risk hot spots is valuable information for railway constructors and operators in terms of network and risk management. Such information allows e.g. the targeted planning and implemen- tation of (technical) risk reduction measures. For instance, the flood damage maps for the Mur River catchment clearly show a considerable increase in both the number of affected track sections and the share of higher damage classes with decreasing flood event probability. Furthermore, besides the main risk areas along the course of the Mur River, additional risk areas along certain tributaries can be easily identified (see Fig. 3 and Sect. 3.1).

To effectively prioritize the implementation of technical protection measures at the risk hot spots identified, decisive aspects such as the EAD or the importance of affected operational sections could be used as a basis. In the study at hand, the EADs were computed on the operational level, ranked in ascending order and compared to the equally ranked track utilization figure of the respective section (reference year 2013) in order to assess the current prioritization of risk reduction measures (see Sect. 3.2). The comparison of the rankings indicates that - from a risk management perspective - the (past) prioritization of risk reduction measures reflects the exposure to floods, as for the operational sections showing a comparatively high EAD only relatively low track utilization was recorded, and vice versa (see Table 2). In other words, the most important sections with regard to their specific train frequencies already present comparatively low economic flood risks, whereas the sections that are faced with higher risk values (i.e. EAD values) only have a comparatively minor relevance with respect to railway service.

Besides economic risks, however, there are further substantial aspects to be considered in the decision-making process. Herein, safety for passengers and personnel is the key premise for a railway operator. Three degrees of increased risk aversion were thus implemented in the estimation of the EAD in order to investigate their impact on the risk quantification and, in particular, to provide a revised foundation for decision-making with regard to the implementation of risk reduction measures (see Sect. 2.6). Results show that the consideration of a risk aversion factor of 10 already induces a triplication of the EAD value of all operational sections, although the overall share of low-probability events only amounts to $25 \%$ in the Mur River catchment (see Table 4, Sect. 3.1 and 3.2). The increase in EAD values is on a similar scale for the risk aversion factors 50 and 100. As the findings show, risk aversion has a strong impact on the economic risk of railway infrastructure in the Mur catchment - and probably also in the rest of Austria. Hence, the consideration of risk aversion against low-probability flood events in the context of risk management is seen as expedient as it gives new incentives for the planning and implementation of risk reduction measures.

In recent years, the railway operation in Austria had to cope with serious financial losses as a result of flooding and other natural hazards. The Morava flood event in Lower Austria in 2006, for instance, caused direct economic losses of more than EUR 41 million (Moran et al., 2010a; ÖBB Infrastruktur AG, personal communication, 2014; Kellermann 
et al., 2015), and the severe flooding in May and June 2013 in large parts of Austria even led to costs of more than EUR 75 million (see Sect. 1). As the examples demonstrate, natural events can cause serious economic loss and, hence, require appropriate risk-financing solutions. Therefore, the superordinate institution of the Austrian (state-owned) railway operator, i.e. the Federal Ministry of Transport, Innovation and Technology (BMVIT), offers a risk compensation mechanism that aims to enable the railway operator to better cope with the economic impacts of natural hazards. In other words, the BMVIT sporadically accumulates financial reserves, which may be drawn upon by the railway operator in case of disastrous natural events. A review of recent annual reports of the railway operator reveals that such hazardrelated funds were provided in 2006 (no amount specified), in 2013 (EUR 18.4 million) and in 2014 (EUR 7.2 million) to support the recovery from damage caused by natural events.

In order to illustrate the potential benefit of comprehensive risk information for the development as well as for the evaluation of risk compensation strategies, a simple thought experiment can be carried out: if we assume that the exposure of the Austrian railway network to flooding is equal (or very similar) to the exposure of the subnetwork within the Mur catchment, the flood risk information obtained for the Mur catchment can be used to estimate the theoretical annual demand of the railway operator for risk compensation of the entire railway network in Austria. More specifically, the EAD of the subnetwork can be extrapolated on the basis of the ratio between the length of the entire railway network of Austria (approx. $5841 \mathrm{~km}$ ) and the length of the subnetwork (approx. $408 \mathrm{~km}$ ). In terms of figures, the resulting ratio of approx. 14.3 can be used as a multiplier for the EAD value of the subnetwork (see Table 1), which results in an EAD value of approx. EUR 125.7 million of the entire railway network of Austria. A comparison of this value with the actual demand in recent years (see above) indicates a realistic dimension of the RAIL model estimates. Furthermore, the substantial amount of potential annual economic loss provides important indications of the decision-making towards an enhanced risk financing strategy, in particular with regard to climate change and possible consequences. This aspect will require close attention and might become of growing importance, as climate change could jeopardize the sustainability of current flood risk management practices.

\subsection{Flood risk and climate change}

The hypothesis that frequencies of river floods in Europe may increase in the future due to climate change is widely discussed among scientists (Hall et al., 2014; Blöschl et al., 2015). Lehner et al. (2006) as well as Dankers and Feyen (2008), for example, concluded that the frequency (and magnitude) of flooding in large parts of Europe is projected to increase in future, i.e. in the period 20712100 using the period 1961-1990 as reference. In particular, flash and urban floods, triggered by local intense precipitation events, are likely to be more frequent throughout Europe (Kundzewicz et al., 2006; Christensen and Christensen, 2007). In accordance therewith, the study on future frequencies of (hydro-)meteorological extremes in Austria by Kellermann et al. (2016a) revealed an increase in the frequency

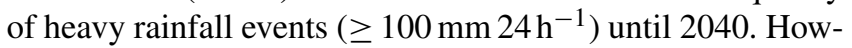
ever, the IPCC (2012) stated that the projections of changes in flood frequencies (and magnitudes) are subject to considerable uncertainties, since e.g. only limited evidence can be produced from river discharge simulations due to the complexity of the causes of regional changes of river flooding. Furthermore, future trends of climatic extremes cannot be projected with sufficient reliability, in particular with respect to heavy rainfall, which considerably contributes to raingenerated local flooding in most cases (Hanel and Buishand, 2010; IPCC, 2012).

Blöschl et al. (2011) presented a study addressing the issue of changing flood frequencies in Austria due to climate change. According to them, the above-mentioned complexities and uncertainties also apply on the national level, which makes a reliable projection of future trends nearly impossible against current knowledge. Therefore, they used five different "if-then" scenarios to describe possible future trends in Austria. For example, one scenario is based on the assumption that the intensity of convective rainfall events will increase in future (2021-2050, in comparison to 1976-2007), and another one implies a rising snow line in the same period. In order to consider the regional complexities of flood generation, the Austrian territory was divided into 10 regions taking into account the hydroclimatic situation and, subsequently, every region was analysed individually each represented by a typical, yet hypothetical, area of approx. $500 \mathrm{~km}^{2}$. Therein, one region is considered as being representative for the Mur River catchment. Blöschl et al. (2011) concluded that, in general, the consistency of trend analyses for Austria depends heavily on the underlying observation period, which indicates that the high natural variability of flooding in the past may remain significantly higher than the expected impacts due to climate change. With regard to the Mur River region, no significant trends in the time series of flood events of the Mur River and its tributaries were identifiable. However, the consideration of the scenario of increasing convective rainfall intensities led to an increase in the magnitude of a 100-year flood by around $7 \%$, whereas the other scenarios have no significant influence (Blöschl et al., 2011). Accordingly, the question rises whether (and to what extent) this $7 \%$ increase might bring implications for the current flood risk situation in the catchment. This question cannot be answered unambiguously due to the above-mentioned uncertainties in the projection of climate extremes. However, since research provides some indications for an increase in the frequency of both heavy rainfall (see Kellermann et al., 2016a) and floods (see Lehner et al., 2006; Dankers and Feyen, 2008), an exacerbation of 
the current flood hazard profile in Austria must be considered. Consequently, the damage and loss estimates presented in the study at hand might be no longer representative and, if no action is taken, the costs due to flood events must be expected to rise in the future.

\section{Conclusions}

The main objective of this study was to provide information on potential flood risk hot spots as well as on expected flood damage on the large scale in order to support strategic flood risk management and decision-making of the Austrian railway operator ÖBB. Therefore, the flood damage model RAIL was applied to estimate structural damage as well as direct economic loss to railway infrastructure in the Mur River catchment. The risk information obtained was then investigated in terms of its sensitivity to changes in model assumptions and, furthermore, evaluated while also taking into consideration different degrees of risk aversion.

The mapped results of the damage estimation (see Fig. 3 and Sect. 3.1) indicate that the RAIL model is basically capable of identifying and localizing risk hot spots at larger spatial scales. Such information can create added value for a railway operator, for example, with regard to supporting the planning and implementation of structural risk reduction measures (e.g. embankments). Further possible application fields of RAIL within flood risk management include the calculation of EAD values on the operational level (see Table 2 and Sect. 3.2). As the study demonstrated, the potential economic loss of an operational section, in conjunction with the individual importance, can be used to effectively prioritize the implementation of such measures or to assess the current status of prioritization, respectively. Finally, the RAIL model also allows the user to investigate the impact of risk aversion on the quantification of risk and, thus, to revise the basis for decision-making with regard to costs and benefits of implementing risk reduction measures. Indeed, the results show that the consideration of risk aversion has a marked impact on the economic flood risk of railway infrastructure in the study area (see Table 4 and Sect. 3.4). Against the background that the key premise of the ÖBB is to ensure safety for passengers and personnel, the risk-adjusted EAD values can be a key argument within decision-making processes.

Looking at the results of the sensitivity analysis (see Table 3 and Sect. 3.3), it appears that the model uncertainties of RAIL are at an acceptable level as the loss estimates revealed no marked sensitivity to the modification of the two key assumptions within the model application. Accordingly, since the results can be regarded as rather robust, an application on the national level is striven for in order to enlarge and strengthen the information basis for risk management of railway infrastructure in Austria.

However, the validity of the results could not yet be properly assessed due to the lack of documented damage and loss data from the Mur River catchment. Although the ÖBB already established an event and damage documentation system for natural hazards in Austria, the given data quality is still not sufficient to provide detailed and process-oriented information on the impacts of flooding (and other hazards) and, hence, hampers the model validation. Therefore, in order to afford a deeper understanding of natural hazards and damaging processes as well as in order to facilitate the derivation of reliable flood damage models, future risk management activities should put special emphasis on the enhancement of standardized event and damage documentation procedures.

\section{Data availability}

The underlying research data of this study are subject to a data license agreement made with the proprietor ÖBB. Therefore, the data are not publicly accessible and, hence, cannot be provided.

Acknowledgements. The authors gratefully acknowledge the Austrian Federal Railways (ÖBB) for their substantial data supply and Florian Mühlböck from the engineering office riocom for his collaboration, data supply and advice concerning the exposure analysis of the Mur River catchment. The research leading to these results has received funding from the EU Seventh Framework Programme through the project ENHANCE (Enhancing risk management partnerships for catastrophic natural hazards in Europe) under grant agreement no. 308438 .

Edited by: S. Fuchs

Reviewed by: two anonymous referees

\section{References}

BABS: Katastrophen und Notlagen in der Schweiz (KATARISK), Eine Risikobeurteilung aus der Sicht des Bevölkerungsschutzes, Bundesamt für Bevölkerungsschutz (BABS), Bern, 83 pp., 2003.

Blöschl, G., Viglione, A., Merz, R., Parajka, J., Salinas, J. L., and Schöner, W.: Auswirkungen des Klimawandels auf Hochwasser und Niederwasser, Österreichische Wasser- und Abfallwirtschaft, 63, 21-30, 2011.

Blöschl, G., Gaál, L., Hall, J., Kiss, A., Komma, J., Nester, T., Parajka, J., Perdigao, R. A. P., Plavcová, L., Rogger, M., Salinas, J. L., and Viglione, A.: Increasing river floods: fiction or reality?, WIREs Water, 2, 329-344, doi:10.1002/wat2.1079, 2015.

BMLFUW (Bundesministerium für Land- und Forstwirtschaft, Umwelt und Wasserwirtschaft) (Ed.): Kosten-NutzenUntersuchungen im Schutzwasserbau - Richtlinie KNU gemäß $§ 3$ Abs. 2 Ziffer 2 WBFG, Fassung Jänner 2008, 28 pp., 2008.

BMLFUW (Bundesministerium für Land- und Forstwirtschaft, Umwelt und Wasserwirtschaft) (Ed.): Hydrographisches Jahrbuch von Österreich 2011, Vienna, Austria, 119, 967 pp., 2013. 
BMLFUW: Nationaler Hochwasserrisikomanagementplan RMP 2015, GZ: BMLFUW-IL.99.1.1/0191-IV/2015, Bundesministerium für Land- und Forstwirtschaft, Umwelt und Wasserwirtschaft, Stubenring 1, 1010 Wien, available at: http://wisa.bmlfuw.gv.at/fachinformation/hochwasserrisiko/ hochwasserrisikoplan/managementplan.html, last access: May 2016, 2015.

Brauner, M.: Themenschwerpunkt 2: Infrastruktur für die Schiene, Oral presentation at the FFG Project Kick-off Meeting, Vienna, Austria, 4 November 2011.

Bubeck, P., de Moel, H., Bouwer, L. M., and Aerts, J. C. J. H.: How reliable are projections of future flood damage?, Nat. Hazards Earth Syst. Sci., 11, 3293-3306, doi:10.5194/nhess-11-32932011, 2011.

Christensen, J. H. and Christensen, O. B.: A summary of the PRUDENCE model projections of changes in European climate by the end of this century, Climatic Change, 81, 7-30, 2007.

Dankers, R. and Feyen, L.: Climate change impact on flood hazard in Europe: An assessment based on high-resolution climate simulations, J. Geophys. Res., 113, D19105, doi:10.1029/2007JD009719, 2008.

Eisenbahngesetz: Gesamte Rechtsvorschrift für Eisenbahngesetz 1957, Fassung vom 14.10.2016, Bundesgesetz über Eisenbahnen, Schienenfahrzeuge auf Eisenbahnen und den Verkehr auf Eisenbahnen, available at: https://www.ris.bka.gv.at/GeltendeFassung.wxe?Abfrage=

Bundesnormen\&Gesetzesnummer=10011302 (last access: October 2016), 2016.

European Union: Directive 2007/60/EC of the European Parliament and the Council of 23 October 2007 on the assessment and management of flood risk, Official Journal of the European Union, L 288/27-34, 2007.

Fartek, S., Hornich, R., Novak, J., and Stania, K.: 10 Jahre Ständige österreichisch-slowenische Kommission für die Mur, Ständige österreichisch-slowenische Kommission für die Mur, Bundesministerium für Land- und Forstwirtschaft, Umwelt und Wasserwirtschaft, Vienna, Austria, 2001.

Fuchs, S., Keiler, M., and Zischg, A.: A spatiotemporal multihazard exposure assessment based on property data, Nat. Hazards Earth Syst. Sci., 15, 2127-2142, doi:10.5194/nhess-152127-2015, 2015.

Hall, J., Arheimer, B., Borga, M., Brázdil, R., Claps, P., Kiss, A., Kjeldsen, T. R., Kriauciuniene, J., Kundzewicz, Z. W., Lang, M., Llasat, M. C., Macdonald, N., McIntyre, N., Mediero, L., Merz, B., Merz, R., Molnar, P., Montanari, A., Neuhold, C., Parajka, J., Perdigão, R. A. P., Plavcová, L., Rogger, M., Salinas, J. L., Sauquet, E., Schär, C., Szolgay, J., Viglione, A., and Blöschl, G.: Understanding flood regime changes in Europe: a state-of-the-art assessment, Hydrol. Earth Syst. Sci., 18, 27352772, doi:10.5194/hess-18-2735-2014, 2014.

Hanel, M. and Buishand, T. A.: On the value of hourly precipitation extremes in regional climate model simulations, J. Hydrol., 393, 265-273, 2010.

ICPR (International Commission for the Protection of the Rhine): Übersichtskarten der Überschwemmungsgefährdung und der möglichen Vermögensschäden am Rhein, Abschlussbericht: Vorgehensweise zur Ermittlung der möglichen Vermögensschäden, Internationale Kommission zum Schutz des Rheins, Wiesbaden, Heidelberg, Nijmwegen, München, 2001.
IPCC: Managing the Risks of Extreme Events and Disasters to Advance Climate Change Adaptation. A Special Report of Working Groups I and II of the Intergovernmental Panel on Climate Change, edited by: Field, C. B., Barros, V., Stocker, T. F., Qin, D., Dokken, D. J., Ebi, K. L., Mastrandrea, M. D., Mach, K. J., Plattner, G.-K., Allen, S. K., Tignor, M., and Midgley, P. M., Cambridge University Press, Cambridge, UK, and New York, NY, USA, 582 pp., 2012.

Jongman, B., Kreibich, H., Apel, H., Barredo, J. I., Bates, P. D., Feyen, L., Gericke, A., Neal, J., Aerts, J. C. J. H., and Ward, P. J.: Comparative flood damage model assessment: towards a European approach, Nat. Hazards Earth Syst. Sci., 12, 3733-3752, doi:10.5194/nhess-12-3733-2012, 2012.

Kellermann, P., Schöbel, A., Kundela, G., and Thieken, A. H.: Estimating flood damage to railway infrastructure - the case study of the March River flood in 2006 at the Austrian Northern Railway, Nat. Hazards Earth Syst. Sci., 15, 2485-2496, doi:10.5194/nhess-15-2485-2015, 2015.

Kellermann, P., Bubeck, P., Kundela, G., Dosio, A., and Thieken, A. H.: Frequency Analysis of Critical Meteorological Conditions in a Changing Climate - Assessing Future Implications for Railway Transportation in Austria, Climate, 4, 25, doi:10.3390/cli4020025, 2016a.

Kellermann, P., Bubeck, P., Schönberger, C., Kirnbauer, R., Schöbel, A., Aksentijevic, J., and Thieken, A. H.: Deliverable 7.5: Case study synthesis and policy recommendations - Case study: Building railway transport resilience to alpine hazards, Report of the ENHANCE project, 2016b.

Klijn, F., Baan, P. J. A., De Bruijn, K. M., and Kwadijk, J.: Overstromingsrisico's in Nederland in een veranderend klimaat, WL delft hydraulics, Delft, the Netherlands, Q4290, 2007.

Kundzewicz, Z. W., Radziejewski, M., and Pińskwar, I.: Precipitation extremes in the changing climate of Europe, Clim. Res., 31, 51-58, 2006.

Lehner, B., Döll, P., Alcamo, J., Henrichs, T., and Kaspar, F.: Estimating the impact of global change on flood and drought risks in Europe: a continental integrated analysis, Climatic Change, 75, 273-299, 2006.

Maiwald, H. and Schwarz, J.: Schadensmodelle für extreme Hochwasser - Teil 1: Modellbildung und Validierung am Hochwasser 2002, Bautechnik, 91, 200-210, doi:10.1002/bate.201300101, 2014a.

Maiwald, H. and Schwarz, J.: Schadensmodelle für extreme Hochwasser - Teil 2: Erste Schlussfolgerungen aus dem Ereignis vom Juni 2013, Bautechnik, 91, 354-367, doi:10.1002/bate.201300102, 2014b.

Merz, B., Elmer, F., and Thieken, A. H.: Significance of "high probability/low damage" versus "low probability/high damage" flood events, Nat. Hazards Earth Syst. Sci., 9, 1033-1046, doi:10.5194/nhess-9-1033-2009, 2009.

Moran, A. P., Schöbel, A., and Thieken, A. H.: Analyse des Hochwasserrisikos von Eisenbahninfrastrukturen, alpS project 1.19ABC - Final Report, Innsbruck, unpublished, 2010a.

Moran, A. P., Thieken, A. H., Schöbel, A., and Rachoy, C.: Documentation of Flood Damage on Railway Infrastructure, in: Data and Mobility, edited by: Düh, J., Hufnagl, H., Juritsch, E., Pfliegl, R., Schimany, H.-K., and Schönegger, H., AISC 81, Heidelberg, 61-70, 2010b. 
Nester, T., Schöbel, A., Drabek, U., Kirnbauer, R., and Rachoy, C.: Flood Warning System for the Austrian Railways, in: 1st Lakeside Conference on Safety in Mobility, Intelligent, Weather Information Systems and Services in Traffic and Transport, Velden, Austria, 2008.

ÖBB-Infrastruktur AG: Geschäftsbericht 2013, ÖBB-Infrastruktur AG, Wien, 2014.

Otto, A., Kellermann, P., Kirnbauer, R., Kundela, G., Meyer, N., Rachoy, C., Schöbel, A., and Thieken, A. H.: Deliverable 7.2: Development of MSPs - Case study: Building railway transport resilience to alpine hazards, Report of the ENHANCE project, available at: www.enhanceproject.eu, last access: October 2016, 2014.

Papathoma-Köhle, M.: Vulnerability curves vs. vulnerability indicators: application of an indicator-based methodology for debrisflow hazards, Nat. Hazards Earth Syst. Sci., 16, 1771-1790, doi:10.5194/nhess-16-1771-2016, 2016.

Pennning-Rowsell, E. C. and Chatterton, J. B.: The benefits of flood allevation: A manual of assessment techniques, Saxon House, Farnborough, 1977.

Pennning-Rowsell, E. C., Green, C. H., Thompson, P. M., Coker, A. M., Tunstall, S. M., Richards, C., and Parker, D. J.: The economics of coastal management: a manual of benefit assessment techniques, DEFRA, London, 1992.
Penning-Rowsell, E. C., Johnson, C., Tunstall, S., Tapsell, S., Morris, J., Chatterton, J., and Green, C.: The benefits of flood and coastal risk management: a handbook of assessment techniques, Flood Hazard Research Centre, Middlesex University Press, Middlesex, 2005.

Penning-Rowsell, E., Viavattene, C., Pardoe, J., Chatterton, J., Parker, D., and Morris, J.: The Benefits of Flood and Coastal Risk Management: A Handbook of Assessment Techniques, Flood Hazard Research Centre, Middlesex, 2010.

Penning-Rowsell, E., Priest, S., Parker, D., Morris, J., Tunstall, S., Viavattene, C., Chatterton, J., and Owen, D.: Flood and Coastal Erosion Risk Management, A Manual for Economic Appraisal, Routledge/Taylor\&Francis, Abingdon, 420 pp., 2013.

Rahn, H.: Eisenbahndämme und Einschnitte, in: Handbuch Eisenbahninfrastruktur, edited by: Fendrich, L., Springer Verlag, Berlin, Heidelberg, 2007.

Thieken, A., Otto, A., Kellermann, P., Schöbel, A., and Kirnbauer, R.: Deliverable 7.1: Risk Profile of Case Studies - Building Railway Transport Resilience to Alpine Hazards, in: Risk Profile Case Study Using Conceptual Framework: Executive Summary, edited by: Mysiak, J., Report of the ENHANCE project, available upon request by authors, 2013. 